\title{
Anomalous origin of the left anterior descending coronary artery from the pulmonary trunk: recognition in life and successful surgical treatment
}

\author{
MAGDI M EL HABBAL, MARC DE LEVAL, * JANE SOMERVILLE \\ From the Paediatric and Adolescent Unit, National Heart Hospital, London
}

SUMMARY An anomalous origin of the left anterior descending coronary artery from the pulmonary trunk with the right and left circumflex arteries arising from the aorta is very rare ando the diagnosis made only at necropsy. An anomalous coronary artery was suspected owing to unexplained cardiomegaly in a 17 month old girl and the anatomy was defined by angiography. The $\Theta$ anomalous vessel was successsfully reimplanted into the aorta.

Anomalies of origin of the coronary arteries are uncommon. Anomalous origin of only the left anterior descending coronary artery from the pulmonary trunk has been reported in eight cases (seven adults and one infant). We describe the first case of this condition diagnosed and treated successfully by operation in early childhood.

\section{Case report}

A 17 month old symptom free girl was referred from Qatar because of unexplained cardiomegaly detected by routine chest radiography after a chest infection. She was a well-built $(10.95 \mathrm{~kg})$, healthy child. Arterial and venous pulses were normal and blood pressure was $105 / 70 \mathrm{~mm} \mathrm{Hg}$. The left ventricle was enlarged. The second sound was reversed and there was an apical late systolic murmur and a soft short ejection murmur at the upper left sternal border.

Investigations confirmed thalassaemia major with haemoglobin concentration of $123 \mathrm{~g} / \mathrm{l}$. An electrocardiogram recorded three weeks before referral (fig 1) showed evidence of left ventricular hypertrophy and anterolateral myocardial infarction-that is $Q$ waves and ST segment elevation in leads I, aVL, V5, and V6; and $T$ wave inversion in V1-4. A later electrocardiogram showed depression and sharp $\mathrm{T}$ inversion in the same leads. Cross sectional echocardiography showed that the left ventricle was dilated and the lateral wall moved poorly. The ejection fraction was $0 \cdot 29$. The right and left coronary arteries seemed to

Requests for reprints to Dr Jane Somerville, Paediatric and Adolescent Unit, National Heart Hospital, Westmoreland Street, London W1M 8BA.

*Present address: Hospital for Sick Children, Great Ormond Street, London WCIN 3JH. arise from the right and left aortic sinuses respec- $\overleftarrow{c}$ tively (fig 2). Doppler echocardiography detected mild mitral regurgitation. The activity of cardiac $\overrightarrow{0}$ enzymes was increased (creatine kinase 79 IU/1,,$\infty$
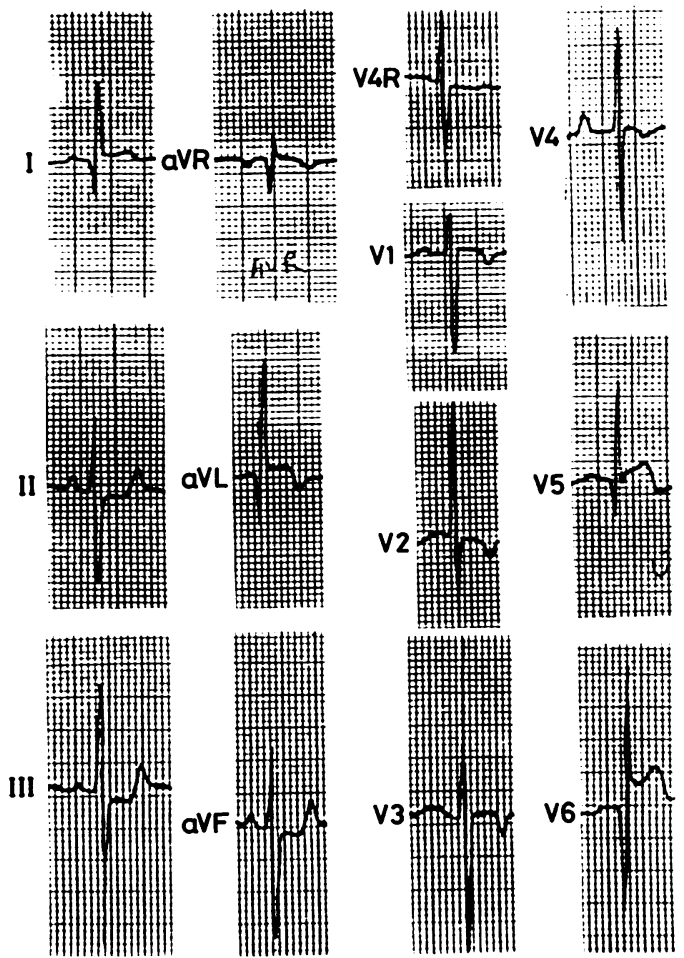

Fig 1 Electrocardiogram showing anterolateral myocardial infarction, $S T$ elevation, and deep $Q$ waves in leads $I, a V L$, and V5-6, with reciprocal $S T$ depression in leads $I I, I I I$, and $a V F$. 


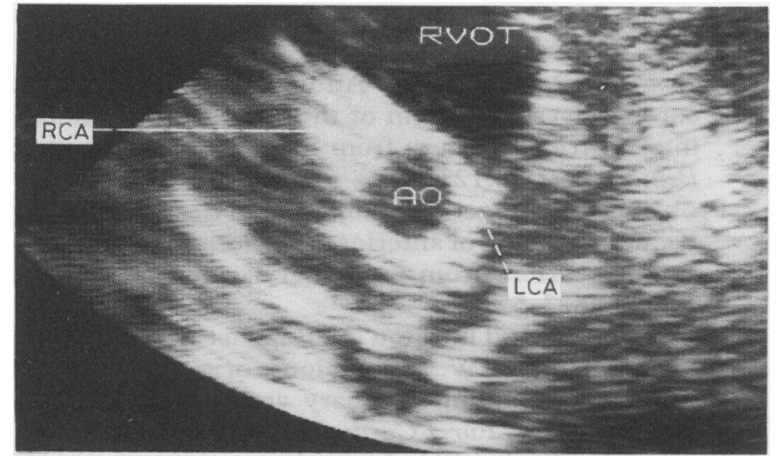

Fig 2 Cross sectional echocardiogram, short axis view above the level of the aortic valve, showing normal origin of the right and left coronary arteries. $A O$, aorta; $L C A$, left coronary artery; $R C A$ right coronary artery; $R V O T$, right ventricular outflow tract.

creatine kinase MB $35 \mathrm{IU} / \mathrm{l}$, and hydroxybutyrate dehydrogenase 262 IU/1).

The clinical diagnosis was that of anomalous left coronary artery with anterolateral myocardial infarction. Pressures measured at cardiac catheterisation were: left ventricle $100 / 18 \mathrm{~mm} \mathrm{Hg}$ and pulmonary trunk $36 / 22 \mathrm{~mm} \mathrm{Hg}$. There was no increase in oxygen saturation in the pulmonary artery. Angiography of the left ventricle showed a dilated chamber with a hypokinetic anterolateral wall. The results of angiography of the right ventricle were normal. Aortic root angiography showed that the right coronary artery was larger than the left coronary artery and that both arose from the usual coronary sinuses. Careful re-examination of the angiogram showed that the left anterior descending coronary artery appeared to fill slightly later than the left coronary artery via scanty collaterals from the right coronary artery; it ascended to empty at a level higher than the origin of the small left coronary artery. Flash opacification of the pulmonary arteries was detected on late pictures.

Anomalous origin of the left anterior descending coronary artery from the pulmonary trunk was diagnosed. Surgical reimplantation of the vessel into the aorta was recommended.

At operation the left anterior descending coronary artery was seen to have a normal diameter and arose from the right posterior sinus of the pulmonary trunk. There was a whitish discoloration of the anterior wall of the left ventricle which was dilated and poorly contracting. The origin of the left anterior descending coronary artery was taken from the pulmonary artery with a cuff of arterial wall. The vessel was dissected to give enough length to reach the left posterior aspect of the ascending aorta and an anastomosis was constructed.

Two weeks after operation, the chest $x$ ray showed some cardiomegaly and the electrocardiogram showed left axis deviation, isoelectric ST segments with deep $Q$ waves in lead I, aVL, V5, and V6, and upright $T$ waves in V1-4. Cross sectional echocardiography showed improved left ventricular function, an ejection fraction of 0.40 , with improved, but still abnormal, motion of the lateral wall of the left ventricle. Doppler echocardiography showed that mitral regurgitation was reduced. The activity of the cardiac enzymes was normal. The patient left hospital three weeks later and has remained symptom free and normally active.

Six months later she was well and active. Chest $x$ ray showed that there had been a further reduction of the heart size, but some cardiomegaly remained, and the electrocardiogram showed a normal axis and deep $Q$ waves in leads $I$ and aVL. Cross sectional echocardiography showed improved left ventricular function, an ejection fraction of 0.45 , with more improvement in motion of the lateral wall of the left ventricle, but this was still abnormal. Doppler echocardiography showed trivial mitral regurgitation.

\section{Discussion}

When a child of less than two presents with unexplained left ventricular failure or hypertrophy the possibility of an anomalous origin of a coronary artery must be considered. In this case, the presence of an electrocardiographic pattern of myocardial infarction was highly suggestive of the diagnosis and for this reason the anomaly was specifically sought.

Cross sectional echocardiography is unreliable for making the diagnosis because two coronary arteries often appear to arise from the root of the aorta. The presence of a segmental area of hypokinesia is suggestive of a localised problem rather than a cardiomyopathy. Angiography of the aortic root or coronary vessels is the most certain method of diagnosis. In this case only the left anterior descending coronary artery was anomalous, and we were temporarily deflected from the correct diagnosis when we saw that the origins of the right and left coronary arteries were normal.

We decided to operate because there was a possibility that the infarction was relatively recent, had come on slowly without symptoms, and that some of the left ventricular dysfunction was recoverable. We hoped for a long term improvement. In the early postoperative period the left ventricular ejection fraction increased, and within six months the heart had become smaller.

Schwartz and Robicsek reported a seven month old female infant who presented with heart failure. ${ }^{1}$ Her electrocardiogram showed myocardial ischaemia 
and she had cardiomegaly on the chest $x$ ray and a normal origin of a small left coronary artery.

Schwartz and Robicsek believed that this was a hypoplastic left coronary artery that was causing ischaemia. The patient later died from acute myocardial infarction and the diagnosis was made at necropsy. The high origin of the left anterior anomalous descending coronary artery had been noted but its significance was not appreciated.

Seven adults aged $18-55$ years have been reported; only one case was male. Angina that required investigation by coronary angiography drew attention to the anomaly. ${ }^{2-4}$ One case presented with fatigue which was attributed to severe mitral regurgitation caused by papillary muscle dysfunction. ${ }^{5}$ Another case was symptom free and attention was drawn to the abnormality by a continuous murmur. ${ }^{6}$ Three patients aged 45,18 , and 55 years had cardiomegaly. ${ }^{457}$ The pattern of anterolateral ischaemia, but not infarction, was shown on the electrocardiogram. Two cases had normal electrocardiograms. ${ }^{35}$ Several surgical treatments have been described and three out of seven patients were alive after 12,25 , and five months. ${ }^{347}$ Although patients survive to adulthood without symptoms, we consider that when the anomaly is identified in childhood it should be corrected in the hope of preventing damage to the left ventricle.

\section{References}

1 Schwartz RP, Robicsek F. An unusual anomaly of the coronary system: origin of the anterior (descending): interventricular artery from the pulmonary trunk. $J$ Pediatr 1971;78:123-6.

2 Probst $P$, Pachinger $O$, Koller $H$, Niederberger $M$, Kaindl F. Origin of anterior descending branch of left $\frac{\bar{\sigma}}{\bar{s}}$ coronary artery from pulmonary trunk. Br Heart $J \overrightarrow{\mathbb{Q}}$ 1976;38:523-5.

3 Donaldson RM, Thornton A, Raphael MJ, Sturridge MF, Manuel RW. Anomalous origin of the left anterior descending coronary artery from the pul-. monary artery. Eur J Cardiol 1979;10:295-300.

4 Singh RN, Taylor PC. Anomalous origin of the left $\omega$ anterior descending coronary artery from the pulmonary artery: surgical correction in an adult. Cathet Cardiovasc Diagn 1983;9:411-6.

5 Baltaxe HA, Wixsom D. The incidence of congenitalanomalies of the coronary arteries in the adult popula- $\varnothing$ tion. Radiology 1977;122:47-52.

6 Roberts WC, Robinwitz M. Anomalous origin of the left anterior descending coronary artery from the pulmonary trunk with origin of the right and left circumflex coronary arteries from the aorta. $A m J_{-}$ Cardiol 1984;54:1381-3.

7 Evans JJ, Phillips JF. Origin of the left anterior ${ }^{\infty}$ descending coronary artery from the pulmonary artery. Three years angiographic follow-up after saphenous vein bypass graft and proximal ligation. Am Coll Cardiol 1984;3:219-24.

\section{Notice}

\section{British Cardiac Society}

The Autumn Meeting will be held at the Wembley Conference Centre, London, on 22 to 24 November 1988. The closing date for receipt of abstracts was 24 June 1988.

The Annual General Meeting for 1989 will take place in Oxford on 6 and 7 April 1989, and the closing date for receipt of abstracts will be 6 January 1989 . 